\title{
Comparison of outcomes of single incision robotic cholecystectomy and single incision laparoscopic cholecystectomy
}

\author{
Sun Min Lee and Jin Hong Lim
}

\begin{abstract}
Department of Surgery, Gangnam Severance Hospital, Yonsei University College of Medicine, Seoul, Korea
Backgrounds/Aims: Multiport laparoscopic cholecystectomy is the standard surgical procedure for symptomatic gallbladder diseases. However, as a result of the ongoing trend toward minimally invasive laparoscopy, single-incision laparoscopic cholecystectomy (SILC) has evolved. Single-incision robotic cholecystectomy (SIRC) can overcome several limitations of manual SILC. The purpose of this study is to evaluate and compare the safety and feasibility of SIRC and SILC. Methods: This study retrospectively reviewed data for all patients who underwent SIRC or SILC from March 2018 to July 2019 in a single institution. The following variables were analyzed: age, sex, body mass index, pain scale, length of stay, and complications. The data were analyzed using the Independent two sample t-test or the Fisher's exact test. Results: A total of 343 patients underwent SIRC or SILC during the study period. After excluding patients with acute cholecystitis, 197 SIRC and 103 SILC patients were analyzed in this study. The surgery time and postoperative hospital stay did not differ between SIRC and SILC. However, the SIRC patients experienced less bile spillage during the surgery than did the SILC patients (SIRC vs. SILC: $24(23.3 \%)$ vs. 11 (5.6\%) cases, respectively; $p<0.001)$. Although there was no difference in the incidence of postoperative complications between procedures, additional pain control was administered more frequently in SILC patients (SILC 1.08 \pm 0.893 , SIRC $0.58 \pm 0.795 ; p<0.001$ ). Conclusions: While both SILC and SIRC are effective for single-incision cholecystectomy, SIRC was superior to SILC in terms of technical stability. Moreover, it has the advantage of postoperative pain control. (Ann Hepatobiliary Pancreat Surg 2021;25:78-83)
\end{abstract}

Key Words: Single incision cholecystectomy; Single port cholecystectomy; Robot assisted cholecystectomy; Laparoscopic cholecystectomy

\section{INTRODUCTION}

Laparoscopic cholecystectomy is the standard treatment for symptomatic gallstones and benign pathologies of the gallbladder, ${ }^{1}$ and the latest evolution of cholecystectomy is single incision surgery. Single incision laparoscopic cholecystectomy (SILC), which was first introduced in 1995 , is considered an effective, minimally invasive method of managing benign gallbladder diseases. ${ }^{2}$ This technique been widely applied in appendectomy, gastric binding, colectomy, donor nephrectomy, and sleeve gastrectomy. ${ }^{3-6}$ It seems to be a no scar surgery because the entry point is hidden in the umbilicus. When compared with multiport laparoscopic surgery, SILC shows better cosmetic outcomes, post-operative pain control, and patient satisfaction, as well as shorter hospital stays. ${ }^{7-9}$

However, SILC is not widely performed because the narrow working space limits the movement of instruments and causes crowding between instruments. ${ }^{10-12}$ In 2011, the da Vinci Single-Site Instrumentation and Accessories (Intuitive Surgical, Inc., Sunnyvale, CA, USA) system was developed to overcome these limitations. ${ }^{12}$ The semirigid instruments cross each other within the trocar, so that the cannula entering from the left becomes the right-side operative instrument and vice-versa. This right to left and left to right conversion system creates an effective working space for instrument movement. The threedimensional endoscope provides extremely fine visualization and avoids the problem of collisions between intra-abdominal instruments. ${ }^{10,12}$ However, the advantage of

Received: November 3, 2020; Revised: November 10, 2020; Accepted: November 12, 2020

Corresponding author: Jin Hong Lim

Department of Surgery, Gangnam Severance Hospital, Yonsei University College of Medicine, 20 Eunju-ro 63-gil, Gangnam-gu, Seoul 06229, Korea

Tel: +82-2-2019-3370, Fax: +82-2-3462-5994, E-mail: doctorjin@yuhs.ac

Copyright (C) 2021 by The Korean Association of Hepato-Biliary-Pancreatic Surgery

This is an Open Access article distributed under the terms of the Creative Commons Attribution Non-Commercial License (http://creativecommons.org/ censes/by-nc/4.0) which permits unrestricted non-commercial use, distribution, and reproduction in any medium, provided the original work is properly cited. Annals of Hepato-Biliary-Pancreatic Surgery • pISSN: 2508-5778 - elSSN: 2508-5859 
single incision robotic cholecystectomy (SIRC) over SILC remains questionable. The aim of this study was to evaluate the feasibility and efficacy of SIRC and to compare clinical outcomes between SIRC and SILC.

\section{MATERIALS AND METHODS}

From June 2018 to February 2019, 343 patients underwent single-incision cholecystectomy, among whom 220 had SIRC and 123 received SILC at Gangnam severance institution. The indications for cholecystectomy were symptomatic gallbladder stone (with or without acute cholecystitis) and gallbladder benign disease (polyps or adenomyomatosis). Due to the high cost of instruments for robotic procedures, SIRC was limited to those who were able to pay an additional expense. The exclusion criteria were patients over 70 years old, patients who could not tolerate single port laparoscopic surgery, and patients with a history of upper abdominal surgery, gallbladder empyema, xanthogranulomatous cholecystitis, pancreatitis, or malignancy. After excluding 43 patients with acute cholecystitis (23 SIRC, 20 SILC), the data from 300 patients (197 SIRC, 103 SILC) were analyzed in this study.

Clinical data were retrospectively collected from the hospital records, including baseline parameters (age, sex, body mass index [BMI], American Society of Anesthesiologists Score Scale [ASA], and diagnosis); perioperative data (surgery time, rate and cause of conversion to open, and intraoperative complications); and postoperative findings (complications, length of stay, pain scale score and the number of additional treatments for pain). The patient's pain was measured immediately upon return to the ward and every 8 hours after the surgery using the visual analog scale (VAS).

\section{Surgical procedure}

All surgeries were performed under general anesthesia with the patient in the supine position. In the SIRC group, the da Vinci Single-Site surgical system was used to perform cholecystectomy. After a $2 \mathrm{~cm}$ vertical incision was made through the umbilicus, a glove port was introduced into the peritoneal cavity, and the pneumoperitoneum was created by injecting carbon dioxide gas under $15 \mathrm{mmHg}$ of intra-abdominal pressure. Curved cannulas were inserted into the port under endoscopic visualization and the robotic surgical system was automatically established. After safe retraction and visualization of Calot's triangle, the cystic duct and cystic artery were skeletonized by Maryland robotic forceps and clipped with Hemo-O-lock clips. The cystic duct and artery were resected by hook electric cutting, and the gallbladder was detached from the liver in a retrograde manner. For SILC, skin incision and glove port insertion were identical to that used in SIRC. A $12 \mathrm{~mm}$ conventional rigid two-dimensional scope and a conventional rigid laparoscopic instrument were then introduced. The gallbladder was manipulated by a laparoscopic grasper, and the cystic duct and cystic artery were skeletonized by a traditional rigid laparoscopic dissector. Hemo-O-lock clips were applied, and the cystic duct and artery were resected by laparoscopic scissors. Again, the gallbladder was detached from the liver in a retrograde manner. For both SIRC and SILC, the fascial defect was closed using a 2-0 monofilament non-absorbable suture, and the skin incision wase closed with absorbable sutures.

\section{Postoperative pain management}

Patients were routinely prescribed $100 \mathrm{mg}$ of Aceclofenac twice a day for pain control. For pain persisting more than 1 hour after pain control, a $50 \mathrm{mg}$ intramuscular injection of tramadol $\mathrm{HCl}$ was administered. If pain persisted after the additional injection, a $30 \mathrm{mg}$ intravascular injection of ketorolac tromethamine was administered after a physical examination.

\section{Statistical analysis}

Continuous variables data are expressed as means \pm standard deviations, while categorical variables are expressed as frequencies and percentages. The Student t test and Fisher's exact test were used as appropriate to analyze and identify statistically significant parameters. Two-tailed $p$ values were calculated, and a $p$ value $<0.05$ was considered statistically significant. All statistical analyses were conducted with the SPSS statistical software (Version 25.0; SPSS, Inc., Chicago, IL, USA).

\section{RESULTS}

There were no significant differences in age, gender, BMI, or ASA score between groups (Table 1). The mean age of SILC and SIRC patients was $48.11 \pm 12.750$ (range, 
Table 1. Patient demographic and clinical characteristics

\begin{tabular}{|c|c|c|c|}
\hline Characteristic & SILC $(n=103)$ & $\operatorname{SIRC}(n=197)$ & $p$ value \\
\hline Age, year, mean $\pm \mathrm{SD}$ & $48.11 \pm 12.750$ & $45.63 \pm 10.461$ & 0.092 \\
\hline Sex, n $(\%)$ & & & 1.000 \\
\hline Male $(\%)$ & $47(45.6)$ & $90(45.7)$ & \\
\hline Female $(\%)$ & $56(54.4)$ & $107(54.3)$ & \\
\hline BMI $\left(\mathrm{kg} / \mathrm{m}^{2}\right)$, mean \pm SD & $24.16 \pm 3.627$ & $24.89 \pm 4.212$ & 0.137 \\
\hline ASA & & & $<0.832$ \\
\hline $1(\%)$ & $31(30.1)$ & $62(31.5)$ & \\
\hline $2(\%)$ & $64(62.1)$ & $123(62.4)$ & \\
\hline $3(\%)$ & $8(7.8)$ & $12(6.1)$ & \\
\hline Preoperative diagnosis & & & 0.748 \\
\hline Chronic cholecystitis (\%) & $77(74.8)$ & $151(76.6)$ & \\
\hline Cholelithiasis $(\%)$ & $12(11.7)$ & $16(8.1)$ & \\
\hline Gallbladder polyp (\%) & $9(8.7)$ & $17(8.6)$ & \\
\hline Gallbladder adenomyosis (\%) & $5(4.9)$ & $13(6.6)$ & \\
\hline Pathologic diagnosis & & & 0.170 \\
\hline Gallbladder adenomyosis (\%) & $1(1.0)$ & $0(0.0)$ & \\
\hline Chronic cholecystitis (\%) & $100(97.1)$ & $185(93.9)$ & \\
\hline Gallbladder polyp (\%) & $1(1.9)$ & $9(1.5)$ & \\
\hline Gallbladder adenoma (\%) & $1(1.0)$ & $3(1.5)$ & \\
\hline
\end{tabular}

SILC, single incision laparoscopic cholecystectomy; SIRC, single incision robotic cholecystectomy; BMI, body mass index; ASA, American Society of Anesthesiologists Scale

Table 2. Perioperative and postoperative outcomes

\begin{tabular}{lccc}
\hline \multicolumn{1}{c}{ Outcome } & SILC (n=103) & SIRC (n=197) & $p$ value \\
\hline Total surgery time, minute & $60.66 \pm 39.810$ & $63.35 \pm 22.185$ & 0.526 \\
Amount of bleeding, ml & $13.98 \pm 52.921$ & $13.58 \pm 65.543$ & 0.954 \\
Conversion rate, n (\%) & $1(1.0)$ & $0(0)$ & 0.343 \\
Bile spillage during surgery, n (\%) & $24(23.3)$ & $11(5.6)$ & $<0.0001$ \\
Postoperative complications & & $3(6.6)$ & 0.707 \\
Wound complication & $0(0)$ & $1(0.5)$ & 0.635 \\
Complication without wound complication & $0(0)$ & $1.46 \pm 0.866$ & 0.098 \\
Length of postoperative hospital stay, day & $1.51 \pm 0.989$ & $0.65 \pm 1.226$ & 0.704 \\
Visual analog scale score of pain & & $5.96 \pm 1.351$ & 0.486 \\
Before surgery & $0.99 \pm 1.876$ & $5.52 \pm 1.188$ & 0.753 \\
Max & $6.02 \pm 1.188$ & $2.43 \pm 0.882$ & $<0.001$ \\
At 1 hour & $5.64 \pm 1.282$ & $0.58 \pm 0.795$ & \\
At discharge & $2.40 \pm 0.856$ & $1.08 \pm 0.893$ & \\
Number of additional pain control treatment, n & & & \\
\hline
\end{tabular}

SILC, single incision laparoscopic cholecystectomy; SIRC, single incision robotic cholecystectomy

16-68) years and $45.63 \pm 10.461$ (range 19-66) years, respectively. The mean BMI was 24.16 \pm 3.627 (range, 15.5132.24 ) $\mathrm{kg} / \mathrm{m}^{2}$ for SILC patients and $24.84 \pm 4.284$ (range, $13.87-44.34) \mathrm{kg} / \mathrm{m}^{2}$ for SIRC patients. Regarding the preoperative and pathological diagnoses, there were no significant differences between SILC and SIRC patients (Table 1).

Table 2 shows the perioperative and postoperative out- comes. The total operating time did not differ between SILC and SIRC $(p=0.526)$ : the mean surgery time for SILC was $60.66 \pm 39.810$ (range, 22-283) minutes and that of SIRC was $63.35 \pm 22.185$ (range, 28-154) minutes. There was no difference in the amount of bleeding between SILC and SIRC (13.98 \pm 65.543 [range, 0-400] $\mathrm{ml}$ vs. $13.48 \pm 52.921$ [range 0-600] $\mathrm{ml}$, respectively, $p=0.954$ ). Bile spillage during the surgery occurred more often with 
SILC $(23.30 \%)$ than with SIRC $(5.6 \%)(p<0.001)$. One patient with SILC was converted to multiport laparoscopic cholecystectomy due to hepatic artery bleeding. There were no cases of open conversion, and no significant difference in the conversion rate between groups.

Although there was no statistically significant difference in postoperative complications between groups $(p=$ 0.707), they were observed in four patients in the SIRC group. One patient developed high fever after discharge. He visited emergency department and was diagnosed with subhepatic abscess by computed tomography and successfully treated with sonographic drainage and antibiotics. The remaining three patients experienced postoperative wound problems: one was diagnosed with incisional hernia and underwent incisional hernioplasty one year after SIRC, and the other two patients had wound seroma.

There was no difference in the average length of the postoperative hospital stay between SILC and SIRC (1.51 \pm 0.989 [range 1-7] days vs. $1.46 \pm 0.866$ [range 1-7] days, respectively, $p=0.635$ ). The preoperative VAS score, postoperative VAS score MAX, and the VAS score at $1 \mathrm{hr}$ after surgery and at discharge were not significantly different between SIRC patients and SILC patients $(p=0.098$, $0.704,0.486$, and 0.753 , respectively). However, additional pain control was administered more frequently in SILC patients than in SIRC patients. (SILC $1.08 \pm 0.893$ vs. SIRC $0.58 \pm 0.795, p<0.001)$.

\section{DISCUSSION}

Since its inception, single incision laparoscopic cholecystectomy has gained popularity as it is associated with better cosmetic outcomes, ${ }^{13,14}$ and trends indicate that it may replace conventional multi-port laparoscopic cholecystectomy. Recently, single incision robot cholecystectomy has been developed to overcome the limitations of SILC. However, there are only a few published studies comparing SILC with SIRC. Thus, in this study, we compared the clinical outcomes of SILC and SIRC and found that SIRC was superior to SILC in the aspects of technical stability and pain control.

Grochola et al. ${ }^{15}$ reported that single incision robot cholecystectomy provides significant benefits in terms of the surgeon's stress load, but they could not show a patient advantage. Furthermore, as there was no reported advant- age in the patient outcome between laparoscopic and robotic cholecystectomy, the increased cost associated with the latter is prohibitive. Han et al. ${ }^{16}$ reported better ergonomics with SIRC because the incidence of bile spillage is more frequent in SILC. However, in that study, the pain was higher for the SIRC patients immediately after the surgery.

During cholecystectomy, care should be taken to avoid perforating the gallbladder. Bile spillage during laparoscopic cholecystectomy can provoke tumor recurrence in patients with a hidden malignancy of the gallbladder. ${ }^{17}$ Many reports have shown that bile spillage negatively affects progression free survival in patients with incidental gallbladder cancer discovered during laparoscopic cholecystectomy. ${ }^{18-20}$ Moreover, bile spillage is a risk for surgical site infection. Peponis et al. ${ }^{21}$ reported that patients who experience bile spillage are over two times more likely to develop surgical site infection. Moreover, Rice et al. $^{22}$ reported that intraperitoneal bile spillage during laparoscopic cholecystectomy was associated with intra-abdominal abscesses. Bile spillage has been associated with old age, high body weight index, and the presence of omental adhesions, ${ }^{21,22}$ which indicates that bile spillage can be an indicator of surgical stability. In our study, we found bile spillage to be more common in SILC patients.

Early postoperative pain following laparoscopy is influenced by several factors, including trauma from the abdominal wall incision, the visceral surgery field range, and peritoneal irritation from the pneumoperitoneum. ${ }^{23,24}$ In addition, it is well-known that visceral and shoulder tip pain have their maximum impact in the first few hours after surgery. ${ }^{23}$ Therefore, it is unlikely that the difference in instrument between SILC and SIRC has a great influence on pain because they are basically the same procedure. It is reasonable to presume that the predominant factor affecting the difference in pain experienced following either SILC and SIRC would be whether the surgery was stably performed, without affecting other abdominal organs, such as the liver and the peritoneum around the surgical site. In our study, there was no significant difference between the two surgical methods regarding the pain experienced immediately after surgery. However, SIRC showed a smaller number of additional pain control treatments; these patients may have experienced more rapid 
pain relief because robotic surgery has a smaller impact on the surrounding organs.

There was no significant difference in the total surgery time between SILC and SIRC in this study. Generally, SIRC has a longer surgery time than SILC does. ${ }^{16,25}$ Han et al. ${ }^{16}$ reported an overall operative time of 56.68 minutes in the SILC group and 101.57 minutes in the SIRC group. Lee et al. ${ }^{25}$ also reported a longer surgery time in the SIRC group. In this study, the surgeon was sufficiently experienced in both SIRC and SILC to overcome the learning curve associated with SIRC. As previously published, the docking time initially had an average learning curve period of about 10 minutes in other institutions, ${ }^{26}$ which was recently reduced to an average of less than three minutes. Thus, after mastering the learning curve, the surgery time for robotic surgery can be markedly shortened. $^{27}$

Although the cosmetic outcome is better in single incision surgery, wound complications have been more frequently reported. ${ }^{28,29}$ In our study, only one patient required conversion to multiport laparoscopic cholecystectomy because of massive bleeding of the hepatic artery, for a total conversion rate of $0.3 \%$. We concluded that the reason for the low open conversion/additional port insertion rate was because the single incision surgery was not performed in patients with a history of upper abdominal surgery, gallbladder empyema, or xanthogranulomatous cholecystitis. In this study, wound complications appeared only in patients who underwent SIRC; however, there was no statistical significance.

A meta-analysis by Sun et al. $^{30}$ found no differences in the surgery time, intraoperative and postoperative complications, length of hospital stay, readmission rate, and conversion rate. between SILC and SIRC. In our study, patients who underwent SIRC demonstrated a significantly positive bile leakage rate and a reduced need for additional pain control compared to patients who underwent SILC. Although bile leakage is not an intraoperative complication, it is a good method for evaluating the stability of cholecystectomy. Moreover, the frequency of additional pain treatment is an alternative method for assessing the effectiveness of surgery.

This study had several limitations. This was a shortterm analysis based on data collected retrospectively from only a single hospital setting. Therefore, large randomized controlled trials are needed to validate the evidence of the SIRC advantage.

This study showed that SILC and SIRC yielded similar perioperative outcomes for most of the measured parameters. Although both SILC and SIRC were effective for single-incision cholecystectomy, SIRC was superior to SILC in terms of technical stability and postoperative pain control.

\section{CONFLICT OF INTEREST}

The authors have no conflict of interest.

\section{ORCID}

Sun Min Lee: https://orcid.org/0000-0003-2901-6957

Jin Hong Lim: https://orcid.org/0000-0002-1970-8223

\section{AUTHOR CONTRIBUTIONS}

Conceptualization: SML, JHL. Data curation: SML, JHL. Formal analysis: SML, JHL. Methodology: JHL. Project administration: JHL. Visualization: SML, JHL. Writing original draft: SML, JHL. Writing - review \& editing: JHL.

\section{REFERENCES}

1. Lee B, Suh SW, Choi Y, Han HS, Yoon YS, Cho JY, et al. Solo single incision laparoscopic cholecystectomy using the parallel method; surgical technique reducing a steep learning curve. Ann Hepatobiliary Pancreat Surg 2019;23:344-352.

2. Navarra G, Pozza E, Occhionorelli S, Carcoforo P, Donini I. One-wound laparoscopic cholecystectomy. Br J Surg 1997;84: 695.

3. Duza G, Davrieux CF, Palermo M, Khiangte E, Azfar M, Rizvi SAA, et al. conventional laparoscopic appendectomy versus single-port laparoscopic appendectomy, a multicenter randomized control trial: a feasible and safe alternative to standard laparoscopy. J Laparoendosc Adv Surg Tech A 2019;29:1577-1584.

4. Patel AG, Murgatroyd B, Ashton WD. Single incision laparoscopic adjustable gastric banding: 111 cases. Surg Obes Relat Dis 2012;8:747-751.

5. Hirano Y, Hiranuma C, Hattori M, Douden K, Yamaguchi S. Single-incision or single-incision plus one-port laparoscopic surgery for colorectal cancer. Surg Technol Int 2020;36:132-135.

6. Omori T, Yamamoto K, Hara H, Shinno N, Yamamoto M, Sugimura $\mathrm{K}$, et al. A randomized controlled trial of single-port versus multi-port laparoscopic distal gastrectomy for gastric cancer. Surg Endosc 2020. doi: 10.1007/s00464-020-07955-0. [in press]

7. Lee YJ, Moon JI, Choi IS, Lee SE, Sung NS, Kwon SW, et al. A large-cohort comparison between single incision laparoscopic cholecystectomy and conventional laparoscopic cholecystectomy from a single center; 2080 cases. Ann Hepatobiliary 
Pancreat Surg 2018;22:367-373.

8. Subirana H, Rey FJ, Barri J, Robres J, Parra L, Martín M, et al. Single-incision versus four-port laparoscopic cholecystectomy in an ambulatory surgery setting: a prospective randomised double-blind controlled trial. J Minim Access Surg 2020. doi: 10.4103/jmas.JMAS_97_20. [in press]

9. Brown KM, Moore BT, Sorensen GB, Boettger CH, Tang F, Jones PG, et al. Patient-reported outcomes after single-incision versus traditional laparoscopic cholecystectomy: a randomized prospective trial. Surg Endosc 2013;27:3108-3115.

10. Lee SH, Jung MJ, Hwang HK, Kang CM, Lee WJ. The first experiences of robotic single-site cholecystectomy in Asia: a potential way to expand minimally-invasive single-site surgery? Yonsei Med J 2015;56:189-195.

11. Migliore M, Arezzo A, Arolfo S, Passera R, Morino M. Safety of single-incision robotic cholecystectomy for benign gallbladder disease: a systematic review. Surg Endosc 2018;32:4716-4727.

12. Kroh M, El-Hayek K, Rosenblatt S, Chand B, Escobar P, Kaouk $\mathrm{J}$, et al. First human surgery with a novel single-port robotic system: cholecystectomy using the da Vinci Single-Site platform. Surg Endosc 2011;25:3566-3573.

13. Marks JM, Phillips MS, Tacchino R, Roberts K, Onders R, DeNoto G, et al. Single-incision laparoscopic cholecystectomy is associated with improved cosmesis scoring at the cost of significantly higher hernia rates: 1-year results of a prospective randomized, multicenter, single-blinded trial of traditional multiport laparoscopic cholecystectomy vs single-incision laparoscopic cholecystectomy. J Am Coll Surg 2013;216:1037-1047; discussion 1047-1048.

14. Phillips MS, Marks JM, Roberts K, Tacchino R, Onders R, DeNoto G, et al. Intermediate results of a prospective randomized controlled trial of traditional four-port laparoscopic cholecystectomy versus single-incision laparoscopic cholecystectomy. Surg Endosc 2012;26:1296-1303.

15. Grochola LF, Soll C, Zehnder A, Wyss R, Herzog P, Breitenstein $\mathrm{S}$. Robot-assisted versus laparoscopic single-incision cholecystectomy: results of a randomized controlled trial. Surg Endosc 2019;33:1482-1490.

16. Han DH, Choi SH, Kang CM, Lee WJ. Propensity score-matching analysis for single-site robotic cholecystectomy versus single-incision laparoscopic cholecystectomy: a retrospective cohort study. Int J Surg 2020;78:138-142.

17. Lee HY, Kim YH, Jung GJ, Roh YH, Park SY, Kang NU, et al. Prognostic factors for gallbladder cancer in the laparoscopy era. J Korean Surg Soc 2012;83:227-236.

18. Blakely AM, Wong P, Chu P, Warner SG, Raoof M, Singh G, et al. Intraoperative bile spillage is associated with worse survival in gallbladder adenocarcinoma. J Surg Oncol 2019;120:603-
610.

19. Clemente G, Nuzzo G, De Rose AM, Giovannini I, La Torre $\mathrm{G}$, Ardito F, et al. Unexpected gallbladder cancer after laparoscopic cholecystectomy for acute cholecystitis: a worrisome picture. J Gastrointest Surg 2012;16:1462-1468.

20. Horkoff MJ, Ahmed Z, Xu Y, Sutherland FR, Dixon E, Ball CG, et al. Adverse outcomes after bile spillage in incidental gallbladder cancers: a population-based study. Ann Surg 2021;273: 139-144.

21. Peponis T, Eskesen TG, Mesar T, Saillant N, Kaafarani HMA, Yeh DD, et al. Bile spillage as a risk factor for surgical site infection after laparoscopic cholecystectomy: a prospective study of 1,001 patients. J Am Coll Surg 2018;226:1030-1035.

22. Rice DC, Memon MA, Jamison RL, Agnessi T, Ilstrup D, Bannon MB, et al. Long-term consequences of intraoperative spillage of bile and gallstones during laparoscopic cholecystectomy. J Gastrointest Surg 1997;1:85-90; discussion 90-91.

23. Kaloo P, Armstrong S, Kaloo C, Jordan V. Interventions to reduce shoulder pain following gynaecological laparoscopic procedures. Cochrane Database Syst Rev 2019;1:CD011101.

24. Cunningham TK, Draper H, Bexhell H, Allgar V, Allen J, Mikl $\mathrm{D}$, et al. A double-blinded randomised controlled study to investigate the effect of intraperitoneal levobupivacaine on post laparoscopic pain. Facts Views Vis Obgyn 2020;12:155-161.

25. Lee J, Kim KH, Lee TY, Ahn J, Kim SJ. Robotic surgery enables safe and comfortable single-incision cholecystectomy: a comparison of robotic and laparoscopic approaches for single-incision surgery. J Minim Access Surg 2020. doi: 10.4103/jmas. JMAS_274_19. [in press]

26. Lim JH, Lee WJ, Choi SH, Kang CM. Cholecystectomy using the Revo-i robotic surgical system from Korea: the first clinical study. Updates Surg 2020. doi: 10.1007/s13304-020-00877-5. [in press]

27. Posada Calderon L, Al Hussein Al Awamlh B, Shoag J, Patel N, Nicolas JD, Scherr DS. The role of surgical experience in patient selection, surgical quality, and outcomes in robot-assisted radical cystectomy. Urol Oncol 2021;39:6-12.

28. Arezzo A, Passera R, Forcignanò E, Rapetti L, Cirocchi R, Morino M. Single-incision laparoscopic cholecystectomy is responsible for increased adverse events: results of a meta-analysis of randomized controlled trials. Surg Endosc 2018;32:3739-3753.

29. Hall TC, Dennison AR, Bilku DK, Metcalfe MS, Garcea G. Single-incision laparoscopic cholecystectomy: a systematic review. Arch Surg 2012;147:657-666.

30. Sun N, Zhang JL, Zhang CS, Li XH, Shi Y. Single-incision robotic cholecystectomy versus single-incision laparoscopic cholecystectomy: a systematic review and meta-analysis. Medicine (Baltimore) 2018;97:e12103. 